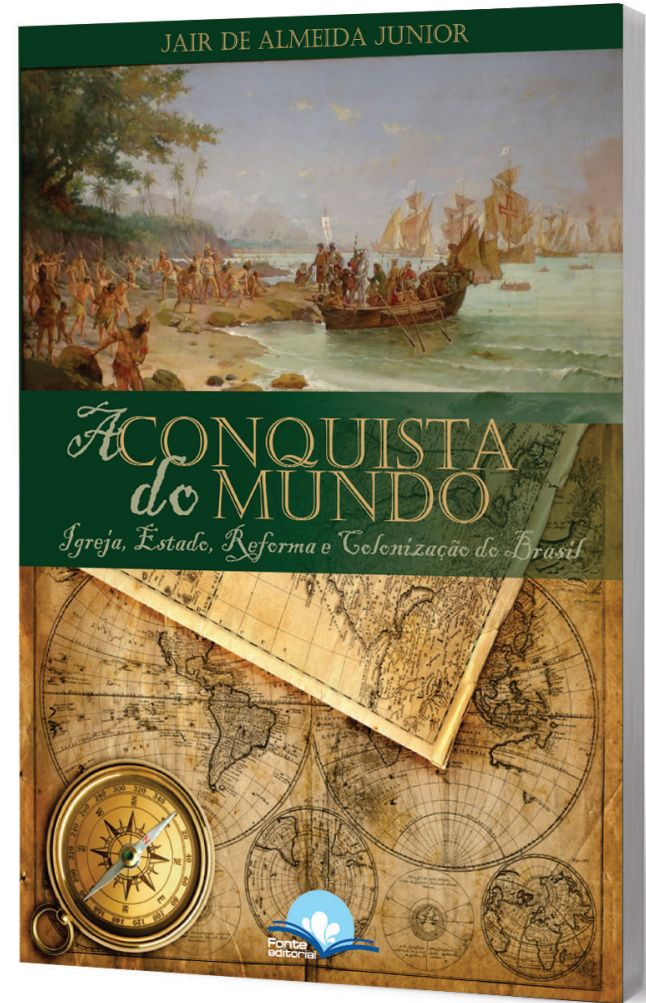

\title{
Dobradiças do temp(l)o
}

\section{Margarida Maria Moura}

A conquista do mundo: Igreja, Estado, reforma e colonização do Brasil, de Jair de Almeida Júnior, São Paulo, Fonte Editorial, 2019, 626 p. 


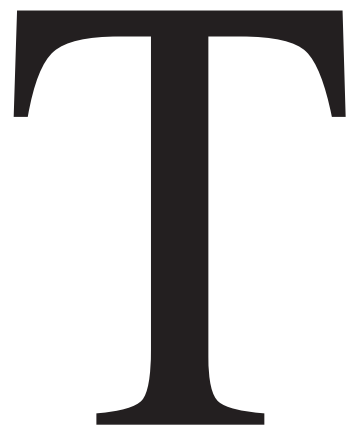

rata-se de trabalho inscrito no âmbito da Cátedra Infante D. Henrique (CIDH) para os Estudos Insulares Atlânticos e a Globalização, acolhida na Universidade Aberta em parceria com o Centro de Literaturas e Culturas Lusófonas e Europeias (Clepul) da Faculdade de Letras da Universidade de Lisboa. Investiga o papel legitimador da religião na colonização do Brasil no século XVI, valendo-se principalmente da experiência dos franceses no estabelecimento da França Antártica na Guanabara, no Rio de Janeiro. Pesquisa de grande erudição, seu ponto de partida está nos estudos da História dos Descobrimentos aberta para conceitos antropológicos, sociológicos e filosóficos. Procede-se a uma profunda irrigação do campo intelectual dos estudos da religião, da política e da sociedade.

Primeiramente, mostra as permanentes fricções e conflitos abertos entre o papado de Roma e reis e imperadores europeus desde a Idade Média. Emerge, então, uma segunda formação de grande saliência: a Reforma Protestante (1536) e a colonização europeia do continente americano (e africano também). Do ponto de vista da Reforma Protestante, o destaque é dado ao luteranismo e ao calvinismo. O luteranismo tem como primeiro sistematizador Martinho Lutero e o calvinismo, João Calvino, que conferem à Bíblia Sagrada, Antigo e Novo Testamento a coluna dorsal exclusiva da prática cristã ${ }^{1}$.

1 A primeira tradução germânica da Bíblia, O Códice de Prata Ulfilas, foi feita pelo bispo gótico Wurfilas (Ulfilas, em grego), que a traduziu no século IV para o gótico, fato anterior ao aparecimento da imprensa que a difunde notavelmente. "O mais sagrado de todos os manuscritos germânicos está escrito em letras prateadas e douradas sobre pergaminho tingido de púrpura, foi só parcialmente preservado, tendo sido descoberto no século XVI na Abadia Werden e levado para Praga e depois para a Suécia e daí desviado para a Holanda. Hoje se encontra na biblioteca da Universidade de Upsala (conforme Rudolph Steiner, O Apocalipse de João, 2000, p. 36).

MARGARIDA MARIA MOURA é livre-docente do Departamento de Antropologia e do Núcleo de Estudos Diversitas da FFLCH/USP e autora de Os herdeiros da Terra (Brazil Publishing). 
No que se pode chamar de uma terceira formação, apresentada na pesquisa realizada, mostra-se como os calvinistas franceses que ficaram conhecidos como huguenotes são os atores sociais constitutivos da França Antártica. Através destes fornece o autor uma ótica e uma prática da colonização do Brasil que se expressa na viagem de Nicolas Durand de Villegagnon à região do Rio de Janeiro.

No último capítulo do livro volta-se à descrição da colonização portuguesa. $\mathrm{O}$ objetivo é marcar um contraponto entre a visão de mundo católica e a visão de mundo calvinista, campo intelectual em que se move o autor. Jair de Almeida Junior escreve inicialmente uma ampla dissertação sobre a relação tensa entre Igreja e Estado na Idade Média europeia. O poder político real e espiritualizado, revestido de uma taumaturgia e calcado na crença religiosa católica. As mais variadas formações históricas europeias atravessam séculos buscando a perpetuidade do poder real ou imperial. É também o período de elevado poder político do papado, ou seja, da Igreja Católica Romana, criando-se duas concepções distintas: a dos reis, entre os quais há reformadores do referido poder, e a da Igreja, que reivindica o ideal papal do estabelecimento de uma sociedade cristã dirigida pela autoridade máxima eclesiástica de então. Essas refregas só tenderam à moderação no século XIV. Segundo Jacques Le Goff há realmente uma longa Idade Média que ele admite se estender até o século XVIII, com eventos revolucionários que conhecemos bem, como a Revolução Francesa e a Revolução Industrial.

Apresenta-se, a seguir, a França Continental. De fato, o território que viria a ter o nome de França sofreu inúmeras mudanças geográficas e político-sociais. As relações sociais no campo têm uma força fundamental em tais mudanças, pois os camponeses são a categoria social que sustentava os senhores feudais que mantinham uma relação de serviço ao rei. Entre os séculos XII e XV o Estado francês se estrutura, pois, amparado pelas leis vigentes, o rei podia impor sua vontade e até confiscar terras de vassalos insubordinados. Produziu-se um fortalecimento gradativo da Coroa com expansão do absolutismo, fato que ocorreu entre guerras, das quais a Guerra dos Cem Anos é extremamente marcante e com grandes epidemias que tiraram vidas em todos os estamentos sociais. O Etat Royal é um Estado dinástico baseado na religião, na honra aristocrática e no clientelismo.

Foi somente em 1536 que o francês radicado em Genebra Jean Calvin (João Calvino) publicou sua mais célebre obra, intitulada $A s$ institutas da religião cristã: piedade diária; centralidade da autoridade bíblica; justificação somente pela fé. De 1534 a 1540, o protestantismo que se propaga na França é basicamente calvinista. Isso nos leva a compreender a complexa figura de Nicolas Durand de Villegagnon. Os anseios democráticos do calvinismo original estavam em contradição com o anseio monárquico de Villegagnon, que aspirava de uma forma meio secreta ser uma espécie de rei do Brasil francês. A Igreja Católica, por seu turno, sentiu-se pressionada não somente pela questão religiosa, mas também pela questão étnica; contudo já estava estabelecida a colonização do Brasil pelos navegadores lusos, cujo rei inaugurou a escravidão inicialmente ameríndia e depois africana com o aniquilamento 
ou a crueldade imposta a populações inteiras, fato paradoxalmente combinado com o surto da obra missionária catequética, que surgiu logo depois. O pensamento missional de Calvino verdadeiramente acreditava fazer de Genebra centro da evangelização mundial, efetuando uma ponte com Villegagnon na Guanabara.

Posteriormente, os trágicos episódios que cercaram a presença francesa no Rio de Janeiro evidenciaram diferentes representações mentais e práticas sociais de Calvino, por um lado, e de Villegagnon, por outro, sobre a colonização da que foi chamada França Antártica. Havia então o Brasil de Cabral, o Brasil de Vespúcio e o Brasil de Villegagnon, e muitos outros que singraram ou aportaram nesta brasílica costa atlântica. Questiona-se se essa presença francesa na Guanabara não faria parte de uma secreta intenção de se iniciar ali uma colônia-refúgio para os protestantes. Uma colônia insular na Guanabara, com autorização para o casamento não somente com mulheres francesas que navegaram até o Brasil, mas com ameríndias. $\mathrm{O}$ autor chama a atenção para o papel civilizador da religião. Estava se abrindo, num universo geográfico muito distante da Europa, uma porta para a dilatação do reino de Jesus Cristo.

Nessa França Antártica destaca-se também a importância de Jean de Léry, que entrou em severas dissenções doutrinárias com Villegagnon. Houve mártires perseguidos e mortos em defesa das verdades dos Evangelhos. Qual delas? Outro Jean, conhecido como Jean Crespin, escreveu na época a história desses mártires. Jean de Léry, por seu turno, apresenta-se compreensivo da cultura ameríndia, dando aos seus textos de época um papel relativizador do compor- tamento cultural no qual, mais do que uma incompreensão do pensamento religioso do europeu, vivenciavam uma indiferença às pregações doutrinárias. Tem sentido aqui dizer que se trata da porosidade da religião ameríndia, muito diferente da visão evangélica protestante armada de fortes vigas para o desempenho do seu papel civilizador. Parece-nos, em primeiro lugar, o papel conversor da religião. Papel este usado pelo autor como condição de base para a colonização. A religião europeia enquadra e a religião ameríndia dissolve. Há uma enorme falta, nesse trecho, de abordagem mais sistemática da cultura e da organização social tupinambá, como nos ofereceu Florestan Fernandes na sua volumosa dissertação de mestrado de 1946. A sociedade ameríndia mereceria por parte do autor um peso mais substancial de discussão antropológica da especificidade opositora ao papel de uma religião que se imbuiu de um projeto civilizador. As menções às sociedades ameríndias, através das citações sobre os encontros e confrontos com a França Antártica que vai se formando na Guanabara, são por vezes genéricas demais. Seria necessária a leitura de pelo menos um clássico da organização social tupi - especificamente tupinambá -, encontrável na obra Organização social dos tupinambá, de Florestan Fernandes. Neste trabalho de grande consistência, um texto sobre o modo de vida tupinambá ofereceria um equilíbrio entre a descrição que o autor faz dos franceses contrapontuando com a descrição dos ameríndios ${ }^{2}$. Florestan, por exemplo, nos diz:

2 Florestan Fernandes, Organização social dos tupinambá: corpo e alma do Brasil, São Paulo, Difusão Europeia do Livro, 1970, p. 94. 
"O princípio fundamental da economia tupinambá consistia na produção do estritamente necessário ao consumo imediato. A acumulação de utilidades como técnica de racionalização dos meios de produção e de coleta era completamente desconhecida. Um velho tupinambá, em um interessante diálogo travado com Léry, revela as suas atitudes a este respeito. 'Uma vez um velho perguntou-me: por que vindes vós outros, mairs e perôs (franceses e portugueses), buscar lenha de tão longe para vos aquecer? Não tendes madeira em vossa terra? Respondi que tínhamos muitas, mas não daquela qualidade [...] retrucou o velho imediatamente: e por ventura precisais de muito? - Sim, respondi-lhe, pois no nosso país existem negociantes que possuem mais panos, facas, tesouras, espelhos e outras mercadorias do que podeis imaginar e um só deles compra todo pau-brasil com que muitos navios voltam carregados. - Ah! retrucou o selvagem, tu me contas maravilhas [...], mas esse homem tão rico de que me fala não morre? - Sim, disse eu, morre como os outros. - E quando morre para quem fica o que deixa? - Para seus filhos se os tem; na falta destes para os irmãos ou parentes mais próximos. - Na verdade, continuou o velho, [...] agora vejo que vós mairs sois grandes loucos [...] pois atravessais o mar e sofreis grandes incômodos, [...] e trabalhais tanto para amontoar riquezas para os vossos filhos ou para aqueles que vos sobrevivem! Não será a terra que vos nutriu suficiente para alimentá-los também? Temos pais, mães e filhos a quem amamos; mas estamos certos de que depois da nossa morte, a terra que nos nutriu também os nutrirá, por isso descansamos sem maiores cuidados".
A partir da observação de ameríndios no século XVI pode-se entender por que colonizar era também evangelizar, só que não concluía inteiramente seu intento. Não era empresa fácil levar adiante tal intento, pois, se já era difícil a catolicidade catequética, que amortece diferenciais ao se estabelecer, imagine as dificuldades do calvinismo, que suprime tudo que lhe é exógeno.

Nada ficou da empreitada da Guanabara? Ou os vestígios são mais sutis? Com relação a São Luís do Maranhão é possível, hoje, frequentar terreiros de candomblé onde se festeja Luís IX (São Luís), em 25 de agosto, quando se canta o seguinte ponto: "Ele é francês/ ele é francês/ São Luís é rei de França/ ele é francês".

A erudição brilha, mas é o trabalho documental que revoluciona o conhecimento. "O indivíduo moderno existe numa pluralidade de mundos, migrando de um lado a outro entre estruturas de plausibilidades rivais e muitas vezes contraditórias, cada uma sendo enfraquecida pelo simples fato de que sua coexistência involuntária se dá com outras estruturas de plausibilidade. Além dos 'outros significantes' que confirmam a realidade, há sempre em toda a parte 'aqueles outros', incômodos refutadores descrentes - talvez o incômodo moderno por excelência", como nos lembra Peter Berger em Rumor de anjos.

Pierre Bourdieu força o autor do livro a um olhar que, ao invés de simplesmente citar, propõe a si próprio o dever de olhar "para um espelho colocado do lado de fora", que também o refletirá. Assim, "contemplando-se como parte da própria cena pode se beneficiar do vivido, mas procurando analisar como alguém que está vendo de fora". Ainda valendo-se de Bourdieu, Al- 
meida Júnior diz: "Embora o campo religioso não seja fato mais difícil de ser analisado do que outros, mistura-se com as convicções pessoais do pesquisador caso ele pertença ou não ao ambiente de crença".

A meu ver a diferença é maior do que em outros campos. E mais difícil de ser analisada, porque se está lidando com ontologia de um autor. Por mais acirrada que seja uma discussão sobre orientações políticas ou orientações metodológicas, as orientações ontológicas são as mais passíveis de vazar para o texto.

É de notável pertinência que formas religiosas que estão em posições subalternizadas numa sociedade tenham voz e escrita com o fim de apresentar, descrever e analisar contextos internos que de outro modo estariam silenciadas ou conhecidas de modo muito fragmentário pelo restante da sociedade. O livro de Jair de Almeida Júnior mostra que se está diante da mesma internalidade; e internalidade participativa e afirmativa de que se valem estudiosos de esferas de culto e religiões subalternizadas.

A questão da objetividade fica realmente no fio da navalha porque o distanciamento crítico se dilui. Essa importante questão epistemológica deveria ter sido antecipada no correr do texto, para que se soubesse desde logo que o ponto de vista do autor tem uma filiação no calvinismo vigente no protestantismo presbiteriano. E no caso não se trata de uma forma de crença subalternizada; de há muito o presbiterianismo está presente em posições de classe abastadas e instruídas da sociedade brasileira, como é o caso de famílias que se pode citar a título de exemplo: Teixeira da Cruz, Themudo Lessa, Lenz Cesar etc. A escolha permite aderir a um texto que esvazia qualquer possibilidade de um viés católico que se sobrepusesse à relevância de uma visão protestante vigente na Europa, especialmente na França Continental e na França Antártica, na tentativa de colonização da Guanabara.

Com essa démarche, pode-se também abrir caminho para uma análise da presença portuguesa no Brasil Colônia, que desencadeia visão crítica da catequese jesuítica, através de um sistema de pensamento que defende a evangelização pela via da Igreja.

A França Antártica se convulsionava com a mesma tensão da França Continental. Tinha-se como missão eliminar o concorrente português, através da expedição capitaneada por Villegagnon, vice-almirante da Bretanha e, paradoxalmente, Cavaleiro da Ordem de Malta, que estava interessado no calvinismo. Pode-se crer que o cavaleiro hospitalário se sentisse contraditório na sua adesão ao projeto calvinista pelos vínculos aqui referidos. Mesmo assim, sabe-se que obteve apoio e conseguiu a simpatia de um dos mais poderosos calvinistas franceses, o almirante Coligny, que se impressionou com o fato de que Villegagnon iria estabelecer no Brasil um refúgio para os protestantes.

A controvérsia religiosa "brasílica" continuou na França ainda durante algumas décadas, especialmente pelos relatos do franciscano André Thévet (pró-catolicismo) e de Villegagnon e Jean de Léry já mencionados.

Houve urgência no pedido feito por Villegagnon aos ministros de Genebra, por meio do Almirante Coligny. Esta urgência era a busca de um frame religioso para a pequena sociedade nascente, porque este era o grande drama de época: a sociedade colonial em gestação ser marcadamente formatada pela religião. 
Jair de Almeida Júnior retorna a Peter Berger, que frisa para qualquer atividade social se abrir à experiência humana pelo vivido e pela apreensão de significados. Franz Boas já nos dizia, em 1889, que “cultura é imposição de significados ao fluxo da experiência"’3. Não há doutrina mais fundante para Calvino do que "a soberania de Deus". A condução dos acontecimentos é chamada de "Providência de Deus". O sucesso de cada empreendimento não pode ser garantido pela simples astúcia humana, mas é concretizado pela "Providência de Deus". Com a viagem ao Brasil, os pastores da Igreja de Genebra renderam "graças a Deus" por abrirem em paragens tão distantes uma porta à dilatação do reino de Jesus Cristo. Mesmo com falta de água potável, pestilências, calor excessivo, ventos contrários, tempestades, intempéries de zona tórrida e vivências muito agudas das diversidades culturais, ainda assim nada se interporia entre eles e o que acreditaram ser uma obra de Jesus Cristo, que se comissionava com o apoio de João Calvino. Uma benção que certamente viria como chancela para tão nobre sacrifício.

Bohannan nos diz: "Não há evidentemente maneira de se atingir um 'fato' que não seja afetado pelo instrumento etnográfico, aquele que apreende o fato. $\mathrm{O}$ sistema concreto permanece necessariamente um mistério. Tudo o que podemos fazer é apreender mais a respeito dos nossos meios sensoriais e mecânicos de percepção de outras extensões extrínsecas deles e da nossa

3 Cf. Margarida Maria Moura, Nascimento da antropologia cultural: a obra de Franz Boas, São Paulo, Hucitec, 2004, p. 173. própria prisão cultural. A comunicação é possível até certo grau, e é o desejo da maior parte das pessoas na maior parte das situações aperfeiçoar este grau" ${ }^{4}$.

A circunscrição temática do Capítulo 3 evidencia que inúmeras vezes uma abordagem mais restrita e mais local da vida social e da cultura apresenta um diferencial notório das abordagens feitas sobre Estados ou nações. As contradições da Guanabara, fragmento de um processo da França Antártica, são multiformes e variadas de tal modo que uma visão do projeto gerado na França Continental e Europeia sequer poderia entrever. É o capítulo mais fascinante do livro, porque é um "conhecimento local", como nos recomendaria Clifford Geertz. Estão implícitas aqui questões consideradas centrais no tratamento da ética protestante na obra de Max Weber, que são os conceitos de chamado e de vocação, ou seja, o sentido de uma concepção religiosa que se vivencia como tarefa estabelecida por Deus. Diz o antropólogo Roberto Motta:

“A questão do chamado não aparece somente nos grandes fundadores do protestantismo; é encontrada também em espanhol e francês para mencionarmos duas línguas românicas, e da pena de autores católicos. Nos exercícios espirituais publicados em 1648 por Inácio de Loyola, o conceito de chamamento divino e escolha desempenha um papel essencial. Tereza de Ávila usa a palavra llamamiento, 'chamamento', pelo menos três vezes na abertura de seu $\mathrm{Ca}$ -

4 Paul Bohannan, "Etnografia e comparação em antropologia", in Shelton H. Davis (org.), Antropologia do direito: estudo comparativo de categorias de dívida e contrato, Rio de Janeiro, Zahar, 1973, p. 109. 
mino de perfeción, originalmente escrito em 1566, tendo exatamente o significado de uma concepção religiosa, de uma 'tarefa estabelecida por Deus'. O conceito e a própria palavra vocação [...], no sentido weberiano: die einer von Gott gestelliten Aufgabe, são claramente encontrados nos escritos de François de Sales (1567-1622), o grande bispo católico de Genebra"5.

Não é o papel civilizador da religião que está em tela nos capítulos 3 e 4, mas o papel dominador das duas formações europeias, a portuguesa e a francesa, para, a partir dele, pôr em prática o papel civilizador da religião. Em primeiro lugar a conquista e depois a catequese ou a evangelização. Assim, são mostrados importantes trechos da história de Portugal. Os elementos distintivos da sua vontade colonial se fortalecem com a figura de Dom Henrique, o navegador, o monarca interessado nas artes e tecnologias náuticas com a criação da Escola de Navegação em Sagres. Aprendem os portugueses dos árabes a esfericidade da Terra, embora Eratóstenes, há mais de 2.200 anos, já tivesse provado que a Terra era redonda. Essas ousadias ocorriam desde o século XV e, com isso, a escravidão africana já enviava pessoas escravizadas para o continente europeu, sediando-as em Portugal.

O fulcro da presença da ordem religiosa jesuítica no Brasil é também fundado na concepção da religião como um fato civilizador. A conversão do ameríndio será bíblica quando se trata dos calvinistas; quando se

5 Roberto Motta, "Weberianism, modernity and the fall of the wall", in Laurence McFalls (ed.), Max Weber's "objectivity" reconsidere, Toronto, University of Toronto Press, 2007, pp. 194-5. trata dos jesuítas, uma ordem católica, ela é eclesial devido à força da noção de igreja para catequese. Descobrem os jesuítas os mesmos problemas de conversão dos ameríndios, já destacados anteriormente. Portugal e seu rei estavam igualmente movidos pelas aspirações de grandeza, de glória e de fé. A catequese jesuítica se permite elaborar em alguns contextos uma cristologia híbrida, em que fatos observados na cultura ameríndia pudessem ser traduzidos de algum modo para a cultura católica, surgindo incongruências nos discursos e nas práticas, argumentação encontrada pelo autor em texto de Alfredo Bosi.

Houve também confrontos entre calvinistas e católicos na bela Guanabara.

Não se trata de refazer a história da colonização portuguesa, mas mostrar as diferenças entre evangelização e catequese. Toma-se como exemplo para exposição a leitura de Vicente T. Lessa, que explora uma dúvida que permanece até os dias de hoje: o poeta mariano das areias, José de Anchieta, como responsável pela morte dos assim chamados mártires da Guanabara.

O trabalho de Jair de Almeida Júnior, mais do que um pós-doutorado, é uma livre-docência no sentido mais clássico desse título, porque investe numa pesquisa de grande erudição, para defender o conhecimento ainda fragmentado de um vasto campo intelectual. É de grande coragem sua abordagem dos dois corpos do rei, feita a partir de sua leitura de Kantorovics, no Apêndice I de sua obra. Numa análise da política brasileira em período anterior à eleição presidencial de 2018, não chegou ele a visualizar que a putrefação do corpo político seria então inaugurada em uma escala de obscurantismo sem precedentes. 